\title{
JOHN HUNTER AND AN AMPUTATION UNDER ANALGESIA IN $1784^{*}$ \\ by
}

\author{
K. BRYN THOMAS, F.F.A.R.c.s. \\ Hon. Librarian, Reading Pathological Society
}

IN I 784, James Carrick Moore, a young surgeon of twenty-one years, published a pamphlet in quarto, 50 pages long, with the title: 'A Method of Preventing or Diminishing Pain in several Operations of Surgery'. The pamphlet bore a dedication: To John Gunning, John Hunter, Charles Hawkins and William Walker, Surgeons to St. George's Hospital, and the dedicatory note states that the author had the advantage of being a pupil and afterwards House-Surgeon of the Hospital. It is addressed from Clifford Street, 20 November I 784 .

Moore's method of diminishing pain was the old one of nerve compression. This is a means which, it is said, was found depicted on a door-post of Saqquarah, circa 2500 B.c. ${ }^{1}$ Benjamin Bell writes in his great System of $1788:^{2}$

It has long been known that the sensibility of any part may not only be lessened but even altogether suspended, by compressing the nerves which supply it. And accordingly, in amputating limbs, patients frequently desire the tourniquet to be tightly screwed, from finding that it tends to diminish the pain. The effect of this, however being inconsiderable, it has lately been proposed by Mr James Moore of London, to compress the principal nerves so completely as to render the parts beneath altogether insensible.

And Bell shows a copper-plate reproduction of Moore's instrument. This picture (Fig. I) is also reproduced by Benjamin Ward Richardson, ${ }^{3}$ while Robinson, ${ }^{4}$ mentioning Moore's work, erroneously figures a tourniquet from Heister ${ }^{5}$ as 'a clamp used for compression anaesthesia'.

The tourniquet had indeed been used for compression analgesia long before, for Paré ${ }^{8}$ quotes three uses for the tourniquet of which 'the third is for that it much dulls the sense of the part by stupefying it: the animal spirits by the straite compression being hindred from passing in by the nerves'.

Moore's paper is typical in its eighteenth-century ornamentation, departing readily into philosophical abstraction with a long apologia for physicians and surgeons who have been accused of a want of feeling or of actual cruelty. 'However,' he says, 'the art of medicine has this advantage over the art of surgery, that the means it uses are less painful: but surgery has this superiority, that it is more certain.' He describes the use of anodynes, opium being the most powerful, but says that the largest dose he dared venture to give had little or no effect in mitigating the sufferings of the patient during operation.

Moore then describes experiments which he made upon himself, using a tourniquet and a pad to compress the sciatic nerve, which led to his discovery that numbness did not occur immediately. This was contrary to his expectations, and the discovery, he suggested, was in opposition to the idea of animal spirits. This theory, derived from Erasistratus of Alexandria, flourishing about

${ }^{*}$ Read to the Osler Glub of London, 8 October 1956. 


\section{K. Bryn Thomas}

270 B.c., and expanded by Galen, postulated that air, entering the lungs, was transferred to the heart via the pulmonary vein, and transformed there into vital spirits. These, carried to the brain, were there converted into animal spirits. The latter passed down the nerves to the muscles, and were believed to ebb and flow in the nerves. Moore says that sudden compression of the nerve should therefore cause immediate loss of sensation, but this, he had shown, was not so.

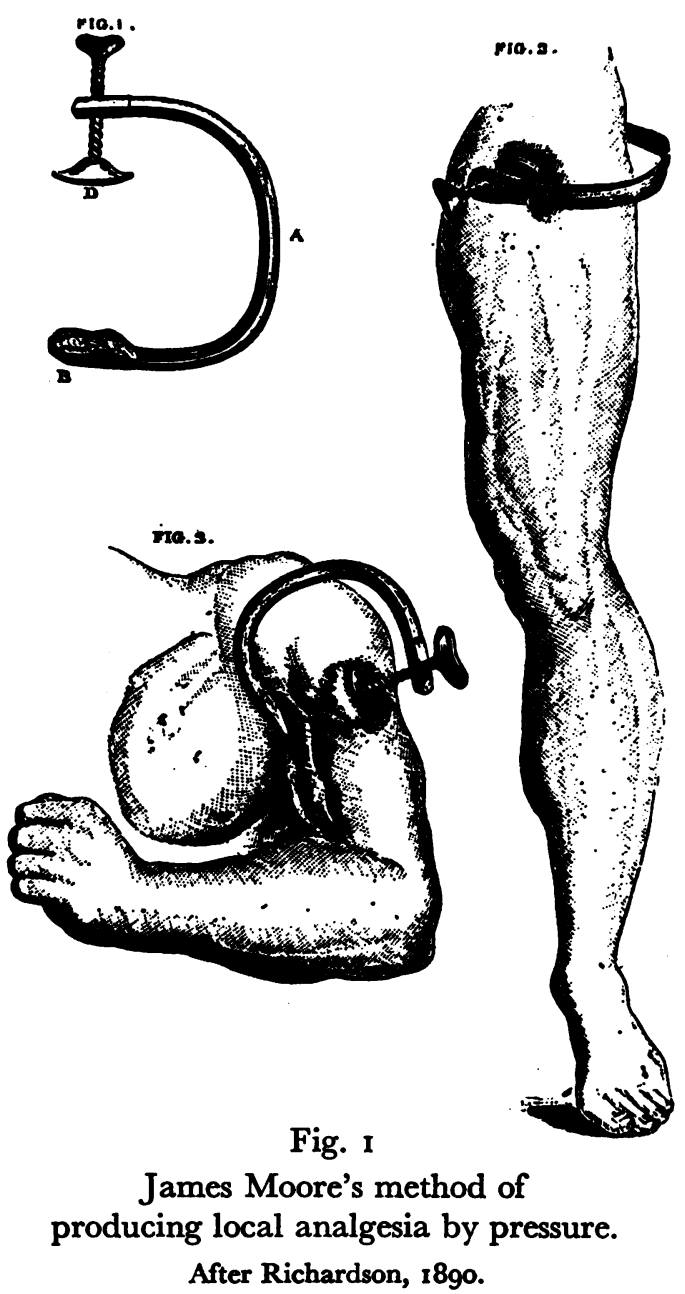

Intending then to use the idea for amputation through the lower leg, Moore gave directions to Mr. Savigny in Pall Mall to make an instrument, a clamp, of which one end is to be placed over the sciatic nerve as it issues from the great sciatic notch, and the other pad over the femoral nerve. No bad consequence is anticipated from the inevitable occlusion of the femoral vessels, but Moore gives a warning that the tourniquet must be used to close anastomosing vessels, and suggests that it be applied some twenty minutes before operating, 


\section{Fohn Hunter and an Amputation under Analgesia in 1784}

in order to blunt the sensibility of those nerves which, arising within the pelvis, descend below the knee, e.g. the lateral and posterior femoral cutaneous nerves, and, occasionally, a branch of the obturator. He also considers possible complications, including paresis, but does not think this dangerous. He was more worried about venous compression for so long a time, thinking that the veins might burst, and suggested venesection as a means of avoiding this, an idea for which Benjamin Bell took him to task, maintaining that further loss of blood might prove harmful to a patient already weakened.

Moore then communicated his views to John Hunter, who offered the opportunity of using the compressor at St. George's Hospital on a man whose leg he was to amputate below the knee.

None of those authors who have commented upon Moore's paper make mention of this use of analgesia by Hunter, no suggestion of it has been found in the various lives of Hunter, and the only indication of it which has been found is that of Keys, ${ }^{7}$ who says merely: 'It is known that John Hunter used it', but gives no reference.

Hunter's patient, who had lost all his toes and had a large and painful ulcer on the foot, was examined by Moore the day before operation, when the compressor was applied as a trial, insensibility of the ulcer being produced, after compression for half an hour.

The next morning compression was commenced at a quarter before eleven o'clock. Numbness followed, and, at a quarter before twelve, the patient was given one grain of opium. A few minutes after twelve the tourniquet was applied, and the amputation performed by Mr. Hunter. Unfortunately, we are not given any of the great man's comments, but we have Moore's own account.

At the circular incision through the skin, the patient did not cry out, change a muscle on his face, or show any symptom of pain. At the subsequent parts of the operation, particularly during the sawing of the bones, he showed marks of uneasiness in his countenance, but did not cry out. As it was thought necessary to take up no less than five arteries the operation lasted a longer time than is normal, and towards the end he grew faintish ... the operation over, the tourniquet was relaxed and I also removed the compressor. But a small vessel bleeding unexpectedly, it was thought necessary to tie it also. Here the patient shewed very strong marks of pain, and afterwards declared that the tying of this last vessel gave him much more pain than all the others.

Questioned later, the patient declared that he had felt hardly any pain, except during the rasping of the bones, as he expressed it. 'This trial', continued Moore, 'had all the success I expected: there was evidently a most remarkable diminution of pain, particularly during the first incision through the skin and muscles. ...?

This experiment does not seem to have struck upon a responsive chord in Hunter's mind amid his other preoccupations-possibly he saw something of its inherent dangers-possibly the experiment was rather less of a success than its originator would have us believe-but the episode provides another instance of the encouragement which John Hunter was always prepared to give to any young man with ideas. We recall Edward Jenner, or Anthony Carlisle, requesting the acceptance of a preparation of the inner ear, and receiving a perpetual 


\section{K. Bryn Thomas}

ticket to Hunter's lectures, or the young gentleman named Thomas who found Hunter dissecting beetles at four o'clock in the morning. ${ }^{8}$

I have not been able to discover if James Moore was one of Hunter's resident pupils, but that he was much under Hunter's influence is shown by two of his later publications. ${ }^{9,} 10$

James Carrick Moore ${ }^{11}$ (1763-1834) was born in Glasgow, second son of Dr. John Moore, ${ }^{11}$ a younger brother of that John who later became better known as Sir John Moore of Corunna.

James Moore in after years was prominent as a friend and staunch supporter of Edward Jenner. He published two vaccination pamphlets in $1806,{ }^{12}$ succeeded Jenner as Director of the National Vaccine Establishment in 1809, and published histories of smallpox ${ }^{18}$ and vaccination. ${ }^{14}$ Twenty-three of Jenner's letters to Moore are reproduced in Baron, ${ }^{15}$ and from them Moore begins to emerge as a medical man of character, with a keen and compassionate interest in his patients. That this was no late development is shown by the story of the twentyone-year-old surgeon who was sufficiently moved by operative suffering to attempt to revive an old method of alleviating pain, and to interest a great surgeon in its use.

\section{REFERENCES}

1. Fülöp-Miller, R., Triumph Over Pain, London, 1938, p. 382.

2. BELL, B., System of Surgery, Edinburgh, I 788, vi, 2nd ed., ch. XLv.

3. Richardson, B. W., Asclepiad, 189o, vin, 336 (Plate opp. p. 355).

4. Roвinson, V., Victory Over Pain, London, 1947, p. 42.

5. Heiste R, L., General System of Surgery, 1768, 8th ed., p. 372, pl. xiv.

6. PARE, A., The Workes of That Famous Chirurgeon Ambrose Parey, trans. by T. Johnson, 1634, p. $45^{8}$.

7. KEYs, T. E., The History of Surgical Anaesthesia, New York, 1945.

8. OT T LE Y, D., in Palmer's Works of Fohn Hunter, 1837, 1, 115.

9. Moore, J., A Dissertation on the Process of Nature in the Filling up of Cavities, Healing of Wounds, etc., 1789. (Prize essay of the Lyceum Medicum Londinense, printed by John Richardson, at the press of John Hunter, Leicester Square.)

10. Moore, J., An Essay on the Materia Medica . . . With some Opinions of Mr. Hunter, 1792. (Dedicated to Matthew Baillie.)

11. Dict. Nat. Biog. 1894, xxxvin, 357, 363 .

12. Moore, J., A Reply to the Antivaccinists, and Remarks on Mr. Birch's Serious Reasons for Uniformly Objecting to the Practice of Vaccination, 1806.

13. Moore, J., The History of the Small Pox, 1815. (Dedicated to Edward Jenner.)

14. Moore, J., The History and Practice of Vaccination, 1817.

15. BARON, J., The Life of Edward Fenner, 1827-38, 2 vols., passim. 